\title{
SSI, SSO, SSE, SSOPI: the elusive language of complications in hernia surgery
}

\author{
J. DeBord ${ }^{1} \cdot$ Y. Novitsky ${ }^{2} \cdot$ R. Fitzgibbons ${ }^{3} \cdot$ M. Miserez $^{4} \cdot$ A. Montgomery ${ }^{5}$
}

Received: 18 June 2018 / Accepted: 19 August 2018 / Published online: 10 September 2018

○) Springer-Verlag France SAS, part of Springer Nature 2018

Wound complications go hand in hand with any surgical procedure, but recently have been increasingly scrutinized as more detailed analyses of outcomes are demanded by providers, payers and patients alike. In this issue of Hernia, Dr. Haskins and associates, have published a stimulating and thought-provoking review of the nomenclature of wound complications using a unique analysis of the 50 most cited papers on ventral hernia repair from 1995 to 2015 [1]. With this group of papers serving as a surrogate for thoughtful and well-designed scientific papers of high quality, a striking absence of a common language with standardized definitions was identified. Why is this?

Perhaps the root cause of these findings lies in the general historical confusion of how best to describe even the most common wound/mesh-related complication. The history of various definitions is worth revisiting. As Haskins et al. point out, a traditional discussion of a wound complication included a surgical site infection (SSI) only. The standardized definition of an SSI developed by the Centers for Disease Control and Prevention (CDC) is an infection that occurs in the part of the body where the surgery took place and includes superficial, deep, and organ space infections and this has become universally accepted. The term surgical site occurrence (SSO) was first introduced by the Ventral Hernia Working Group (VHWG) in 2010 [2]. The VHWG consisted of expert general and plastic surgeons interested in abdominal wall reconstruction who developed a 4-level grading system to aid surgeons in selecting the best

\footnotetext{
J. DeBord

jdebord@peoriasurgical.com

1 University of Illinois College of Medicine at Peoria, Peoria, USA

2 Columbia University, New York, NY, USA

3 Creighton University, Omaha, NE, USA

4 University Hospital Leuven, Leuven, Belgium

5 University Hospital Lund, Lund, Sweden
}

prosthesis to be used for various clinical scenarios. Although the grading system has not been universally adopted, the term surgical site occurrence (SSO) which added wound events that are not captured by the term SSI, including seroma, wound dehiscence, and enterocutaneous fistula has proved to be very useful [3]. Haskins et al. use an expanded list in their definition of an SSO which includes wound cellulitis, non-healing incisional wound, fascial disruption, skin or soft tissue ischemia, skin or soft tissue necrosis, wound serous or purulent drainage, stitch abscess, seroma, hematoma, and infected or exposed mesh in addition to SSI, seroma, wound dehiscence, and enterocutaneous fistula. While many of these SSOs are clinically important, some are either questionably relevant (such as wound cellulitis or an asymptomatic hematoma or seroma) or should be counted as an SSI (fascial disruption, skin/soft tissue necrosis, purulent drainage, stitch abscess, infected mesh, enterocutaneous fistula).

In an attempt to add more clarity to the above definitions, the term of surgical site occurrences requiring procedural interventions (SSOPI) was introduced recently [4]. SSOPI, utilized in only a handful of studies to date, is designed to help capture the more clinically relevant SSOs/SSIs. Haskins et al. suggest that the "term SSOPI is more hernia-specific and can be used by hernia surgeons to compare the outcomes of different surgical approaches and prosthetic materials as they relate to the durability of ventral hernia repairs". While we certainly need a reliable way to compare outcomes in abdominal wall reconstruction, a wound requiring minimal bedside packing or a small seroma drained percutaneously (both SSOPIs) are unlikely to significantly impact the durability of a repair. Moreover, another common metric of wound complications, a surgical site event (SSE) has been used [5-7]. SSEs are defined as all SSIs and clinically relevant SSOs, such as cellulitis, symptomatic seroma/ hematoma, and suture granuloma. In other words, it allows to add to SSIs all other hernia surgery-related wound/mesh issues that are not of infectious etiologies. Finally, despite 
Table 1 Nomenclature for complications in hernia surgery

\begin{tabular}{|c|c|c|c|}
\hline Item & Earliest citation & Hernia specific & Definition (short) \\
\hline Surgical site infection (SSI) & $\begin{array}{l}\text { Centers for Disease } \\
\text { Control and Pre- } \\
\text { vention (CDC) }\end{array}$ & No & $\begin{array}{l}\text { Infection occurring where the surgery took place and includes super- } \\
\text { ficial, deep, and organ space infections }\end{array}$ \\
\hline Surgical site occurrence (SSO) & $\begin{array}{l}\text { Ventral Hernia } \\
\text { Working Group } \\
\text { (VHWG) } \\
\text { Breuing et al. [2], } \\
\text { updated with the } \\
\text { present article }\end{array}$ & Yes & $\begin{array}{l}\text { SSI, seroma, wound dehiscence, enterocutaneous fistula, wound } \\
\text { cellulitis, non-healing incisional wound, fascial disruption, skin or } \\
\text { soft tissue ischemia, skin or soft tissue necrosis, wound serous or } \\
\text { purulent drainage, stitch abscess, seroma, hematoma, and infected } \\
\text { or exposed mesh }\end{array}$ \\
\hline Surgical site event (SSE) & Majumdar et al. [5] & Yes & $\begin{array}{l}\text { SSIs, and clinically relevant SSOs, such as cellulitis, symptomatic } \\
\text { seroma/hematoma, and suture granuloma occurring within } 90 \text { days } \\
\text { of hernia repair }\end{array}$ \\
\hline $\begin{array}{l}\text { Surgical site occurrences requir- } \\
\text { ing procedural interventions } \\
\text { (SSOPI) }\end{array}$ & Baucom et al [4] & Yes & $\begin{array}{l}\text { SSOs requiring a procedural intervention, defined as wound opening } \\
\text { or debridement, suture excision, percutaneous drainage, or mesh } \\
\text { removal }\end{array}$ \\
\hline
\end{tabular}

increasing awareness of potential immunologic and allergic reactions to implanted meshes, none of the definitions in this study included those adverse effects.

Haskins et al. in their conclusion make a plea that all future publications in abdominal wall reconstruction surgery adopt the three definitions of wound morbidity: SSI, SSO, and SSOPI. The authors pointed out an alarming rate of inconsistent reporting in as many as $82 \%$ of the cited articles during the study period. Such a high number is hardly surprising however, given the methodology of the study, as only one of the studied definitions (SSI) was commonly used during the 20 -year study period. The other 2 were either not described for at least the first 15 years of the study (SSO) or not at all within the studied timeframe (SSOPI). While the problem of inconsistencies in reporting and the desire for improvement are valid considerations, the evidence to support the proposed limited 3-definition system falls short of definitive.

Despite potential deficiencies and omissions of the proposed terminology, the authors correctly point out that "the absence of a common language among hernia surgeons has negatively impacted the ability of surgeons to make accurate comparisons among findings within the literature, to have meaningful conversations at scientific meetings, and can negatively impact surgeon and hospital quality measures". We, as abdominal wall reconstruction surgeons, certainly must improve our terminology. We believe the proposed terms of this study should be viewed as a foundation towards establishing the common language for reporting wound complications in the field of abdominal wall reconstruction. We call upon the World Hernia Societies to create a joint task force to establish the definitions for wound events after hernia repair that are accepted and adopted across all continents. This work will not only impact the future of abdominal wall reconstruction literature, but may also help to adopt appropriate terminology across other surgical fields. If we are to accurately report and compare outcomes, at the very least, we should all be speaking the same "language" (Table 1).

\section{References}

1. Haskins IN, Horne CM, Krpata DM et al (February 2018) A call for standardization of wound events reporting following ventral hernia repair. Hernia. https://doi.org/10.1007/s10029-018-1748-6

2. Breuing K, Butler CE, Ferzoco S et al (2010) Incisional ventral hernias: Review of the literature and recommendations regarding the grading and technique of repair. Surgery 148(3):544-558. https://doi.org/10.1016/j.surg.2010.01.008

3. Montgomery A (2013) The battle between biological and synthetic meshes in ventral hernia repair. Hernia 17(1):3-11. https:// doi.org/10.1007/s10029-013-1043-5

4. Baucom RB, Ousley J, Oyefule OO et al (2016) Evaluation of long-term surgical site occurrences in ventral hernia repair: implications of preoperative site independent MRSA infection. Hernia. https://doi.org/10.1007/s10029-016-1523-5

5. Majumder A, Winder JS, Wen Y, Pauli EM, Belyansky I, Novitsky YW (2016) Comparative analysis of biologic versus synthetic mesh outcomes in contaminated hernia repairs. Surg (United States) 160(4):828-838. https://doi.org/10.1016/j. surg.2016.04.041

6. Winder JS, Behar BJ, Juza RM, Potochny J, Pauli EM (2016) Transversus Abdominis Release for Abdominal Wall Reconstruction: Early Experience with a Novel Technique. J Am Coll Surg 223(2):271-278. https://doi.org/10.1016/j.jamcollsur g.2016.04.012

7. Novitsky YW, Fayezizadeh M, Majumder A, Neupane R, Elliott HL, Orenstein SB (2016) Outcomes of Posterior Component Separation with Transversus Abdominis Muscle Release and Synthetic Mesh Sublay Reinforcement. Ann Surg 264(2):226-232. https://doi.org/10.1097/SLA.0000000000001673 